\title{
Reciclagem de copos descartáveis de poliestireno pós-consumo para construção de luminárias pendentes
}

A crescente utilização de materiais poliméricos descartáveis, contrapondo o tempo longo de decomposição, torna necessário pensar em propostas para minimizar o impacto ambiental decorrente do descarte inadequado na natureza. Dessa forma, uma das alternativas é a reciclagem mecânica, possibilitando o resíduo ter viabilidade comercial. Nessa perspectiva o presente trabalho teve como objetivo construir luminárias de poliestireno (PS) reciclado mecanicamente a partir de copos descartáveis. Os copos foram recolhidos quinzenalmente durante seis meses, submetidos à triagem e secagem. Em seguida, triturados, processados via extrusão, granulados e processados via injeção. Os materiais foram analisados através das seguintes técnicas: espectroscopia na região do infravermelho, ensaio mecânico de tração, teste de chama, teste de ausência de cloro (teste de Beilstein) e teste prévio de amarelamento. Foram comparados o PS cristal virgem e o PS reciclado. Após a caracterização, os corpos de prova foram perfurados para construção da luminária pendente. Os resultados dos testes de chama e de Beilstein foram muito satisfatórios. Já as análises de propriedades mecânicas, devido a possível presença de aditivos na composição dos copos descartáveis e/ou a utilização de uma porcentagem de poliestireno de alto impacto, apresentaram resultados referentes a um material reciclado mais elástico, tornando neste caso a luminária mais resistente. As análises de espectroscopia na região do infravermelho, em comparação com outros estudos já realizados para o PS, mostraram resultados muito similares. Em relação ao teste prévio de amarelamento, visualmente nenhuma alteração foi identificada. Portanto, a construção de luminárias pendentes mostrou-se uma alternativa eficaz e sustentável para copos descartáveis pós-consumo.

Palavras-chave: Reciclagem mecânica; Termoplásticos; Copos descartáveis, Poliestireno cristal; Luminárias pendentes.

\section{Recycling post-consumption polystyrene disposable cups for construction of pending luminaires}

\begin{abstract}
The growing use of polymeric materials for single use, opposing the long decomposition time, it is necessary to think about proposals to minimize the environmental impact resulting from the disposal in nature. Thus, an alternative is recycling waste into raw material for commercially viable manufactures. Thus, the present work aims to build mechanically recycled crystal polystyrene (PS) luminaires from disposable cups. The cups were collected fortnightly for six months, subjected to screening and drying. After this stage, the cups were ground and processed in an extruder, the material was cooled in water, dried, and granulated, to be processed by injection in a next step. The materials processed by extrusion-injection were analyzed by the following techniques: infrared spectroscopy, mechanical tensile test, flame test, fusion, Beilstein test and yellowing test. After characterization, the test pieces for the construction of the luminaire were drilled. The mechanical test, as it has additives in the composition of disposable cups, showed a better result than expected, making the recycled material more elastic, which makes the luminaire more resistant. Infrared spectroscopy analyzes, compared to other studies already performed for PS, have very similar results. Regarding the yellowing test, no changes were visually identified. Therefore, the construction of pendant lamps proved to be an effective and sustainable alternative to post-consumer disposable cups.
\end{abstract}

Keywords: Mechanical recycling; Thermoplastics; Disposable cups; Crystal polystyrene; Pendant lamps

Topic: Desenvolvimento, Sustentabilidade e Meio Ambiente

Reviewed anonymously in the process of blind peer

\section{Ana Paula Knopik (id)}

Universidade Tecnológica Federal do Paraná, Brasil

http://lattes.cnpq.br/1508681442501061

http://orcid.org/0000-0003-1674-2888

anaknopik@alunos.utfpr.edu.br

\section{Gabryel Emed da Silva}

Universidade Tecnológica Federal do Paraná, Brasil

http://lattes.cnpq.br/5817384593184086

geds1410@hotmail.com

\section{Michelle Campos de Almeida}

Universidade Tecnológica Federal do Paraná, Brasil

http://lattes.cnpq.br/4631564368908122

michelle mca@hotmailcom
Received: 19/04/2021

Approved: 20/05/2021

Marciel José Zuclinski

Empresa Westaflex do Brasil, Brasi

http://lattes.cnpq.br/6270524400814993

marciel@wdbnet.com

Juliana Regina Kloss

Universidade Tecnológica Federal do Paraná, Brasi

http://lattes.cnpq.br/3968800900294945

http://orcid.org/0000-0002-3632-6219

juliana.kloss@gmail.com

\section{Referencing this:}

KNOPIK, A. P.; SILVA, G. E.; ALMEIDA, M. C.; ZUCLINSKI, M. J.; KLOSS, J. R.. Reciclagem de copos descartáveis de poliestireno pós-consumo para construção de luminárias pendentes. Revista Ibero Americana de Ciências Ambientais, v.12, n.5, p.492-503, 2021. DOI: http://doi.org/10.6008/CBPC2179-6858.2021.005.0039 


\section{INTRODUÇÃO}

A quantidade total de material polimérico produzido globalmente tem passado por um crescimento expressivo, entre o início da produção em 1950 e 2016, por exemplo, ocorreu um aumento de 1,5 para 335 milhões de toneladas (PLASTICS EUROPE, 2008). Esse crescimento está relacionado ao fato de os materiais poliméricos apresentarem muitas vantagens quando comparados, por exemplo, ao vidro ou ao metal. No entanto, devido ao descarte inadequado na natureza, pode vir a causar grandes problemas ambientais, como nos oceanos, que na forma de micropartículas se acumulam na cadeia alimentar dos organismos marinhos (COLE et al., 2011; WRIGHT et al., 2013).

O mercado global de reciclagem de termoplásticos foi avaliado em US $\$ 31,5$ bilhões em 2015 , com crescimento anual previsto de 6,9\% para o período de 2016 até 2024 (TURKU et al., 2018). A reciclagem não só é vantajosa do ponto de vista financeiro, como caminha para um modelo mais próximo da economia circular e consequentemente, mais sustentável. Aumentar a visão de sustentabilidade das indústrias pode trazer novas oportunidades de inovação, competitividade e criação de empregos. Segundo Mrowiec (2018) a economia circular representa um modelo alternativo e mais sustentável à economia linear tradicional. Um modelo linear segue o caminho de fazer, usar e depois descartar. Em contraste, em uma economia circular, ele mantém os recursos em uso pelo maior tempo possível, extraindo deles o valor máximo durante o uso e, em seguida, recupera e regenera produtos e materiais no final de sua vida útil.

Nessa perspectiva o presente trabalho tem o objetivo de construir luminárias pendentes a partir da reciclagem mecânica secundária de copos descartáveis de poliestireno pós-consumo. Essa proposta abre alternativa para transformar o resíduo em matéria prima para manufatura na cadeia de produção, visto que o resultado da luminária construída foi satisfatório.

\section{REVISÃO TEÓRICA}

\section{Poliestireno (PS)}

O PS está disponível, em geral, como: o poliestireno cristal (PS ou GPPS - General Purpose Polystyrene); poliestireno expandido, comercialmente conhecido como Isopor ${ }^{\circledR}$ (EPS - Expanded Polystyrene); poliestireno de alto impacto (PSAI ou HIPS - High Impact Polystyrene) e o mais recente poliestireno sindiotático (também conhecido como XAREC da Idemitsu ou SPS - syndiotactic Polystyrene). As principais aplicações do poliestireno são embalagens alimentícias, descartáveis, brinquedos, materiais escolares e de escritório, eletrodomésticos, utensílios domésticos e construção civil, mas quando não é destinado corretamente após seu uso, tal material se torna um problema para a sociedade.

\section{Impacto Ambiental: o descarte incorreto torna o polímero um contaminante}

Em geral, todo material é degradável, no entanto, alguns levam mais tempo do que outros para se decompor, como é o caso de grande parte dos polímeros. Essa característica aliada à sua grande produção e utilização, com a falta de gerenciamento de resíduos, faz com que esses materiais acabem contaminando diversos locais (SPINACÉ, 2005). 
Entre 60 e 95\% da poluição marinha são provenientes de objetos poliméricos de uso único (ou SUP, single-use plastic) como canudos, copos, pratos e talheres descartáveis (SCHNURR et al., 2018), com encontrado na costa da Bulgária (SIMEONOVA et al.., 2019), nos rios da Indonésia (KURNIAWANet al., 2019), praias e dunas da Colômbia (BUITRAGO et al.., 2018), dentro de tartarugas marinhas no Brasil (RIZZII et al.., 2019), seja na forma de micro-plásticos nas praias das Filipinas (PALER et al., 2019), nas praias eslovenas (KOREZ et al., 2019), nas aguas e praias do Sri Lanka (KOONGOLLA et al., 2018).

Diante dos dados apresentados, uma das preocupações levantadas pelo elevado consumo de tais objetos, somado com o fato de uma parte gerada acabar no meio ambiente, é a geração de microplásticos (MPs) e/ou nanoplásticos (NPs). Antes de serem completamente decompostos, o copo descartável de poliestireno, por exemplo, vai ser transformado em partículas de 5-40 mm (mesoplástico), subsequentemente em partículas de 1-5000 $\mu \mathrm{m}$ (MPs) e, por fim, chega a 0,1 $\mu \mathrm{m}$ ou menor (NPs). Esse processo se dá através de ações físicas, químicas e biológicas, incluindo forças mecânicas, calor, luz ultravioleta, oxidação e biodegradação (PENG et al., 2020).

Assim, alternativas são necessárias, como por exemplo, aproveitamento energético em coprocessamento, polímeros biodegradáveis, reutilização e reciclagem, sendo esta última opção promissora quando bem estudada, especialmente para o poliestireno.

\section{Reciclagem Mecânica: etapas do processo}

A reciclagem é definida como conjunto de técnicas de reaproveitamento de materiais sem utilidade aparente, que foram ou serão descartados, tornando-os um novo produto, com um novo ciclo produtivo. Existem quatro tipos de reciclagem: primária, secundária (ou mecânica), terciária (ou química) e quaternária (ou energética). A reciclagem primária é geralmente feita na própria indústria que gerou o resíduo; tal material se encontra limpo e a identificação não é necessária, pois se entende que a fonte é de absoluta confiabilidade. $\mathrm{O}$ produto é muito próximo daquele que utilizou matéria virgem, em termos de propriedades.

$\mathrm{Na}$ reciclagem secundária o resíduo tem fonte pós-consumo, os quais são basicamente provenientes de resíduos sólidos urbanos. As propriedades do produto necessariamente são inferiores em relação a produtos feitos de matéria virgem (STRAPASSON, 2004). A reciclagem terciária ocorre quando o processo utilizado para reciclar é baseado na despolimerização, onde é promovida a decomposição química controlada do material, obtendo produtos oligômeros, monômeros e substâncias de baixa massa molar que, posteriormente, poderão ser submetidos a novos processos de polimerização, processamento, industrialização e utilização.

$\mathrm{Na}$ reciclagem quaternária é feita combustão do material para aproveitamento energético. Os materiais poliméricos usados em embalagens de alimento ou matéria orgânica demonstram um valor combustível positivo para a combustão total (FORLIN et al., 2002). Segundo Zanin et al. (2004) o processo de reciclagem mecânica secundária segue as etapas demonstradas na Figura 1. 


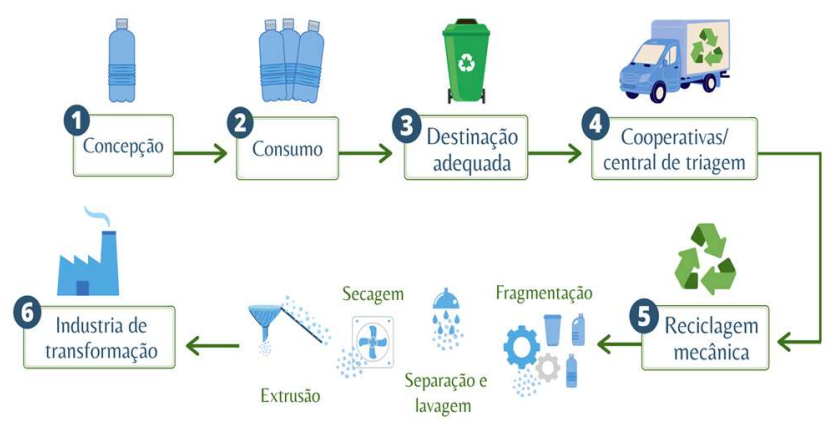

Figura 1: Esquema do processo de reciclagem mecânica secundária

Detalhando um pouco mais sobre as etapas, a separação consiste na classificação por tipo, cor ou finalidade, este último se refere ao conteúdo que era armazenado na respectiva embalagem; a moagem tem por finalidade reduzir o tamanho do material. 0 resultado são flocos com o tamanho e formato desejado para as próximas etapas. Na sequência, a lavagem é um tipo de separação de contaminantes e termoplásticos através da água. Os contaminantes podem ser terra, areia, papéis, outros polímeros, matéria orgânica e, é importante ressaltar que o enxágue só existe se na etapa de lavagem foram utilizados produtos químicos e tem por fim retirar resquícios dos detergentes, sabões e soda cáustica.

Para finalizar tem-se a secagem que consiste na retirada da água dos flocos na etapa de lavagem, enxágue ou estocagem, a aglutinação, etapa destinada à reciclagem de filmes plásticos como sacos e sacolas ou produtos de espessura fina e não altera a densidade dos flocos, mas sim a densidade aparente dos mesmos e ainda, o processamento ou transformação que pode ser via extrusão, injeção, rotomoldagem, calandragem, pultrusão, moldagem por compressão, termoformagem (ZANIN et al., 2004).

\section{Reciclagem do Poliestireno: alternativas de reaproveitamento energético}

O poliestireno vem sendo estudado para explorar novas aplicações a este material há mais de 20 anos. Araújo (1997) preparou blendas de poliestireno com borracha, resíduos de pneus e da indústria de calcados, e obteve um composto intermediário entre o PS e o HIPS (High Impact Polystyrene), com resistência a tração menor do que o PS tradicional e resistência ao impacto maior, mas que não chega a do HIPS. Recentemente, Motta (2016) produziu uma argamassa modificada com poliestireno sulfonado feito de copos descartáveis, e o resultado foi uma melhor retenção de água, resistência à adesão, menor absorção de água por capilaridade, ao mesmo tempo em que impede que esse resíduo acabe poluindo o meio ambiente.

Outra aplicação sintetiza compósitos de poliestireno reciclado (obtido de embalagens de alimentos) com algodão, utilizando poucos passos e poucos reagentes. O material obtido permite a remoção de óleo da água, podendo ser usado na remoção de hidrocarbonetos policíclicos aromáticos. São três implicações ambientais desse método: permite a reciclagem de resíduos de poliestireno; propõe uma maneira quase sem solvente e realista (sem equipamentos sofisticados e caros) de reciclagem; e o compósito ainda pode ser utilizado para remediação ambiental (MEHMANDOST et al., 2019).

Diante do que foi apresentado até o momento e tendo em vista o crescente desenvolvimento dos materiais poliméricos este projeto fundamenta-se em encontrar uma solução viável para os resíduos 
termoplásticos de PS, que não envolvam aterros sanitários e que possam ser realizados em lugares diversos.

\section{METODOLOGIA}

Foram utilizados para realização deste trabalho copos descartáveis de PS cristal de $50 \mathrm{ml}$ e $200 \mathrm{ml}$; poliestireno cristal 688G DOW STIRON68G, da Chemical Company em pellets; acetona P.A $\left(\mathrm{CH}_{3}\right)_{2} \mathrm{CO}$ PM: 58,08 mol.L-1 , CAS: 67-64-1, da marca REATEC; xilol P.A $\left(\mathrm{C}_{8} \mathrm{H}_{10}\right)$ PM: 106,17 mol..-1 , CAS: 1330-20-7, da marca Dinâmica; placas de Petri; balança analítica, marca SHIMADZU AUY 220. Foram coletados copos descartáveis de PS de $50 \mathrm{ml}$ e $200 \mathrm{ml}$, em seguida, realizada a triagem, separando os contaminantes como papéis e outros materiais plásticos. É importante ressaltar que não foram separados os copos por cor, tendo amostras transparentes e brancas, sendo a maioria transparente.

Os copos foram processados em um extrusora monorosca de laboratório, marca BGM ${ }^{\circledR}$ modelo EL45, com diâmetro da rosca de $25 \mathrm{~mm}$, razão comprimento/diâmetro (L/D) de 40:1, velocidade da rosca de 325 rpm. Após extrusão, os fios de PS reciclado foram submetidos ao granulado, da marca PIOVAN, para facilitar a etapa de injeção dos corpos de prova. Os grânulos de PS reciclado foram submetidos ao processo de moldagem por injeção, utilizando uma injetora Romi modelo Primax 65R, com pressão de injeção de 150 bar com tempo de recalque de 2 minutos e a temperatura nas quatro zonas adaptada entre 200 e $250^{\circ} \mathrm{C}$ com molde para corpos de prova de tração, seguindo as normas ASTM D 638-3.

Os corpos de prova gerados foram submetidos às seguintes análises: espectroscopia na região do infravermelho com transformada de Fourier (FTIR), ensaio mecânico de tração, teste de chama, teste de ausência de cloro (teste de Beilstein) e teste prévio de amarelamento. Os ensaios foram realizados a uma resolução de 4,0 cm $\mathrm{cm}^{-1}$, no intervalo de 4000 a $400 \mathrm{~cm}^{-1}$ e 64 scans e com o acessório de refletância total atenuada (ATR - Attenuated total reflection - reflectância total atenuada). O equipamento utilizado foi da marca Bruker, Tensor 27, Platinum ATR e cristal de germânio. Os corpos de provas obtidos pelo processo de injeção foram submetidos ao ensaio mecânico de tração, no equipamento AG-I SHIMADZU SPL - 10 KN, mas condições de $5 \mathrm{~mm} \cdot \mathrm{min}^{-1}$ de velocidade de afastamento das garras e célula de carga de $10 \mathrm{kN}$. As curvas de tensão por deformação foram obtidas avaliando dez corpos de prova para PS cristal virgem e dez para PS reciclado.

Esta avaliação consistiu na queima e observação visual do material polimérico quando em contato com a chama. Foi verificado a cor da fumaça, odor, cor da chama, se houve a presença de gotejamento ou não, e se continuou queimando após remoção da chama. O teste de Beilstein permite a deteç̧ão rápida dos compostos clorados em alguns polímeros e, é realizado a partir do aquecimento de um pedaço de cobre metálico até a incandescência. Na sequência, toca-se o metal rapidamente na amostra de termoplástico e coloca-se novamente na chama, o surgimento de coloração de chama verde corresponde a um resultado positivo para a presença de cloro.

O teste consistiu na adaptação de uma caixa fechada de madeira com dois compartimentos, um deles com lâmpada fluorescente de $13 \mathrm{~W}, 50-60 \mathrm{~Hz}$, da marca TASCHIBRA e outro com lâmpada LED de 7 
W, $60 \mathrm{~Hz}$, da marca VITRALUX, ambas com 9,0 cm de espaçamento, que é correspondente a distância da lâmpada em relação às hastes da luminária. O teste foi realizado em duplicata num período de três semanas.

Os corpos de prova foram furados com uma furadeira de bancada SCHULZ modelo FSB 13P PRATIKA, com o auxílio de brocas com espessuras de $4,0 \mathrm{~mm}, 7,9 \mathrm{~mm}$ e $8,0 \mathrm{~mm}$, sequencialmente formando uma fenda (Figura 2), possibilitando o encaixe delas.

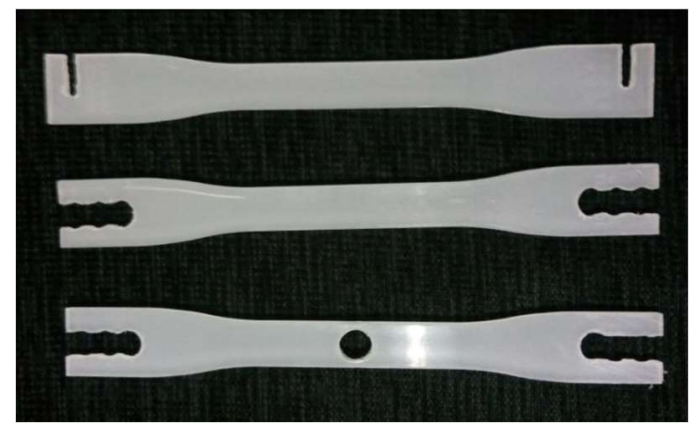

Figura 2: Preparação dos corpos de prova para construção das luminárias

Para auxiliar na construção da luminária pendente foi elaborado um projeto gráfico, através do programa PHOTOSHOP CS3 (Figura 3) e estabelecido que fossem utilizados 12 corpos de prova, um fio com bocal e uma lâmpada.

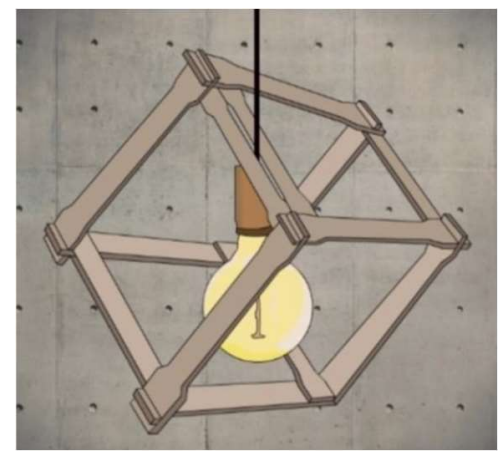

Figura 3: Projeto da luminária pendente utilizando o PHOTOSHOP CS3

\section{RESULTADOS E DISCUSSÃO}

Os copos descartáveis coletados eram de uso exclusivo para consumo de água, não necessitando da etapa de lavagem. Desta forma, realizou-se a triagem dos copos, e quando detectado umidade excessiva, a secagem era feita a temperatura ambiente, deixando-os na bancada do laboratório por 48 horas ou até que toda água visível fosse evaporada. Para o processamento do material (copos cortados), a extrusora foi regulada a temperatura de $170{ }^{\circ} \mathrm{C}$ na zona 1 , onde ocorre a entrada de material; $240{ }^{\circ} \mathrm{C}$ na zona $2 ; 245{ }^{\circ} \mathrm{C}$ na zona 3 e na matriz, zona $4,205{ }^{\circ} \mathrm{C}$, variando $3{ }^{\circ} \mathrm{C}$ para mais ou para menos, tendo um perfil de temperatura então entre 170 e $260^{\circ} \mathrm{C}$.

Porém, após trinta a quarenta minutos de processamento notou-se dificuldade devido ao fato do material ser muito leve, sendo necessária uma ajuda manual para passar pela rosca, então para melhor fluidez na saída da matriz, foi aumentada a temperatura para a seguinte configuração: $175{ }^{\circ} \mathrm{C}$ na zona 1 ; $250{ }^{\circ} \mathrm{C}$ na zona $2 ; 260{ }^{\circ} \mathrm{C}$ na zona 3 e $210{ }^{\circ} \mathrm{C}$ na zona 4 , variando $3{ }^{\circ} \mathrm{C}$ para mais ou para menos. Em seguida, os fios foram resfriados em água, enrolados e encaminhados para granulação. Os granulados de PS 
reciclado foram encaminhados para a injeção dos corpos de prova. No início na injeção, notou-se novamente dificuldade com a leveza e o tamanho dos fios (granulados) do PS reciclado, sendo que estes acabaram amolecendo, grudando uns aos outros e fazendo com que o material não fluísse adequadamente pela rosca. Foi necessário então selecionar pedaços menores e aumentar a temperatura de injeção.

Separados os granulados menores, com pressão de injeção de 150 bar e a temperatura nas quatro zonas entre 200 e $250{ }^{\circ} \mathrm{C}$, sendo ainda necessário afastar o funil alimentador para colocar o material diretamente na entrada da rosca, ele foi injetado no molde. $O$ tempo de recalque foi de 2 segundos, sendo injetados o PS cristal virgem e o PS reciclado. Em seguida, serão apresentados os resultados das análises de Espectroscopia na região do infravermelho com transformada de Fourier, ensaio mecânico de tração e testes comuns realizados na indústria de reciclagem mecânica e termoplásticos em que os corpos de provas de PS foram submetidos. Posteriormente, será feita a comparação dos resultados das análises com a literatura referente ao PS virgem.

Os espectros obtidos para o poliestireno reciclado (Figura 4a) e virgem (Figura 4b) revelam as bandas: entre 3100 e $3000 \mathrm{~cm}^{-1}$, característica de $\mathrm{v}\left(=\mathrm{CH}\right.$ ) de anel aromático; entre 2950 e $2840 \mathrm{~cm}^{-1}$, de v(C$\mathrm{H})$; em 1600, 1492 e $1450 \mathrm{~cm}^{-1}$ referente à v(C=C) do anel aromático; $\delta(\mathrm{C}-\mathrm{H})$ em $1027 \mathrm{~cm}^{-1}$; entre 730 e 770 $\mathrm{cm}^{-1}, \gamma(\mathrm{C}-\mathrm{H})$; e por fim, a deformação do anel fora do plano, $710-690 \mathrm{~cm}^{-1}, \gamma(\mathrm{C}=\mathrm{C})$. Os resultados estão condizentes aos já apresentados na literatura para este material polimérico (FERREIRA et al., 2015; MALOSTE et al., 2019; AYELERU et al., 2019; JALAL et al., 2019).
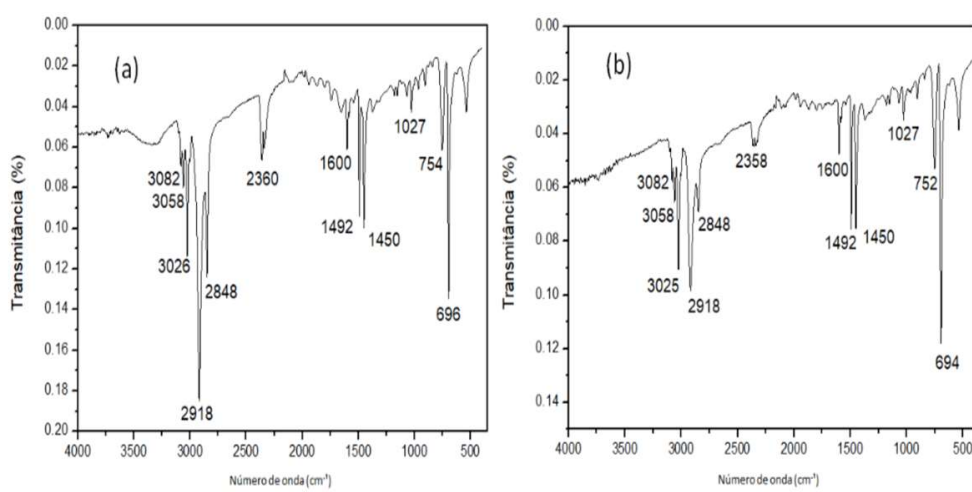

Figura 4: Espectros na região do infravermelho do poliestireno reciclado (a) e do poliestireno virgem (b)

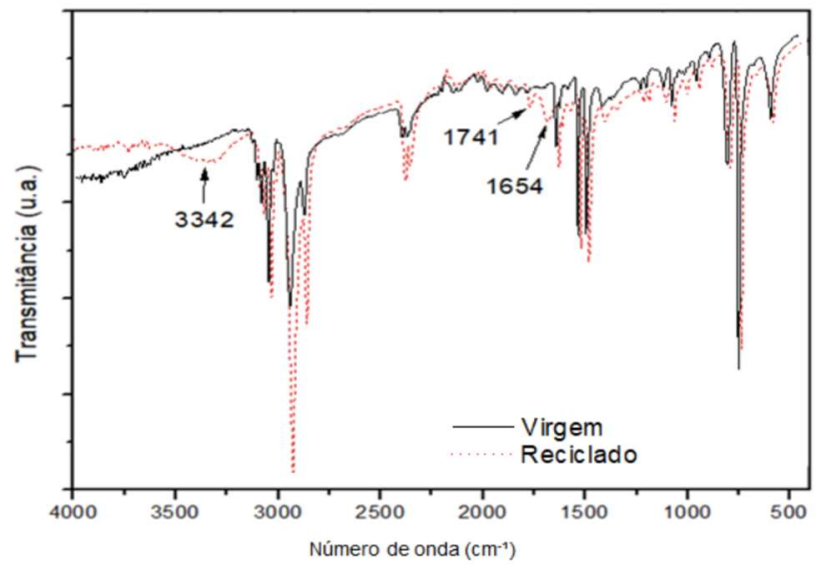

Figura 5: Espectro na região do infravermelho do poliestireno reciclado e do virgem sobrepostos

Quando se sobrepõe os espectros do PS virgem e do reciclado (Figura 5) torna-se possível observar 
algumas mudanças do material reciclado em relação ao virgem, destacando-se o surgimento de três bandas: em 3342, 1741 e $1654 \mathrm{~cm}^{-1}$.

Uma das atribuições para as alterações nas bandas pode ser relativa aos aditivos usados pela indústria de copos descartáveis. Em $3342 \mathrm{~cm}^{-1}$, podem-se sugerir grupos funcionais comuns dessa faixa como $v(\mathrm{O}-\mathrm{H})$ ou $\mathrm{v}(\mathrm{N}-\mathrm{H})$. Já a banda de $1741 \mathrm{~cm}^{-1}$, pode ser um éster $\mathrm{v}(\mathrm{C}=\mathrm{O})$, tendo em vista que sua faixa de absorção vai de 1750 até $1735 \mathrm{~cm}^{-1}$, ou ainda, pode ser relativo a um dos aditivos, comuns empregados, o carbonato de cálcio $\left(\mathrm{CaCO}_{3}\right)$. A banda, de $1654 \mathrm{~cm}^{-1}$, pode ser atribuída a $\mathrm{v}(\mathrm{C}=\mathrm{N})$, pois este agrupamento absorve entre 1690 e $1640 \mathrm{~cm}^{-1}$, inferindo na presença de nitrogênio juntamente com a de $3342 \mathrm{~cm}^{-1}$. Não obstante, existe outra possibilidade de ser uma amida indicada de 1680 a $1630 \mathrm{~cm}^{-1}$, valores que correspondem a $v(\mathrm{C}=\mathrm{O})$ e $\delta(\mathrm{N}-\mathrm{H})$, sendo que numa amostra sólida, essas duas bandas geralmente se sobrepõem (BARBOSA, 2007).

A partir do ensaio mecânico das amostras foi possível construir as curvas de tensão-deformação para os materiais. A figura 6 foi elaborada com a média das amostras selecionadas de poliestireno virgem e reciclado.

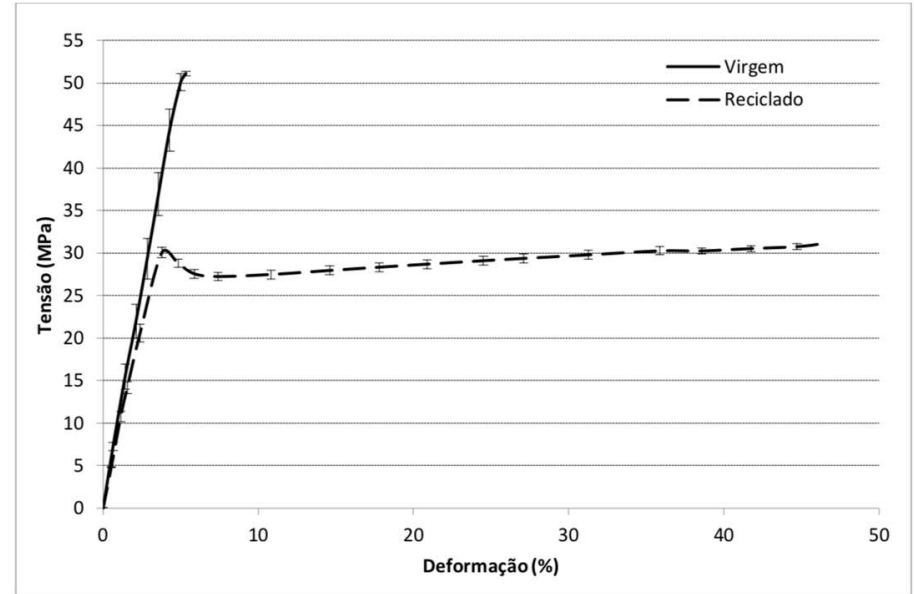

Figura 6: Gráfico de tensão - deformação das amostras de poliestireno virgem e reciclado

Na Tabela 1 apresenta-se o tempo, em segundos, que foram verificados para cada corpo de prova se romper, foi um parâmetro importante para se comparar, pois na média, o reciclado demorou seis vezes mais.

Tabela 1: Tempos obtidos (em segundos) até o rompimento dos corpos de prova no ensaio de tração

\begin{tabular}{ccc}
\hline & Virgem & Reciclado \\
\hline $\mathrm{T}_{1}$ & 38,00 & 240,70 \\
$\mathrm{~T}_{2}$ & 37,60 & 337,65 \\
$\mathrm{~T}_{3}$ & 41,30 & 248,40 \\
$\mathrm{~T}_{4}$ & 38,60 & 239,70 \\
$\mathrm{~T}_{5}$ & 41,10 & 325,60 \\
$\mathrm{~T}_{6}$ & 38,45 & 109,00 \\
$\mathrm{~T}_{7}$ & 34,25 & 149,80 \\
$\mathrm{~T}_{8}$ & 41,35 & 251,95 \\
$\mathrm{~T}_{9}$ & 38,70 & 262,70 \\
$\mathrm{~T}_{10}$ & 39,65 & 238,80 \\
\hline Média & 38,90 & 240,43 \\
\hline
\end{tabular}

No caso do poliestireno virgem, quando comparado à amostra reciclada, este apresentou um comportamento homogêneo, rompendo num valor mais baixo, ou seja, sempre próximo de 5,0 a 5,6\% de 
deformação, e ainda, demonstrou melhor resistência à tensão. Tal padrão de comportamento era esperado na amostra virgem, um polímero frágil (CALLISTER JUNIOR, 1991; YEMAH et al., 2010; BOTAN et al., 2015).

Os resultados dos corpos de prova do PS reciclado, também representados na figura 6 , romperam em torno de $40 \%$ a $45 \%$ na deformação e cerca de $30 \mathrm{MPa}$ na tensão. Ainda, foi possível observar o comportamento de três corpos de prova que destoaram, suportaram mais tensão e deformaram menos do que a maioria das amostras. Por se tratar de um material que foi submetido a mais formas/vezes de processamento, ou seja, o poliestireno cristal virgem foi processado apenas via injeção, enquanto o poliestireno de copos pós-consumo passou pelos processos de termoformagem, extrusão e injeção, esperava-se uma perda nas suas propriedades (VILAPLANA et al., 2006) e o material reciclado poderia então vir a ter uma menor deformação e apresentar uma menos tensão, pois se trata de um polímero frágil. Mas, o teste mostrou que as amostras recicladas tendem para um polímero com características de elastômeros (CALLISTER JUNIOR, 1991).

Após este comportamento sugere-se, corroborando com as análises de FTIR, que pode se ter a presença de aditivos e/ou ainda, a mistura com poliestireno de alto impacto, pois se obteve um material com propriedades muito mais próximas a esta classe de poliestireno. Vale a pena ressaltar que as três amostras que destoaram nos resultados, ainda estavam aptas para construção de luminárias pendentes e, esta diferença foi atribuída a algum problema no sistema de injeção, pois o corpo de prova se rompeu exatamente em uma falha que parecia ser uma bolha de ar.

O PS virgem, após dez segundos na chama, apresentou fumaça preta com fuligem, odor característico e gotejamento ao retirá-lo da chama. O PS reciclado teve comportamento próximo, porém, com mais fuligem e gotejamento mais denso e demorado. $O$ aumento de fuligem e mudança de gotejamento podem também estar relacionado aos aditivos adicionados na produção de copos descartáveis e/ou por se tratar de um material que passou por diferentes formas de processamentos.

O surgimento da chama verde ao levar a argola de cobre com amostra de poli (cloreto de vinila) (PVC) é resultado da presença de cloro. Como esperado tanto no poliestireno virgem quanto no reciclado não houve mudança na coloração da chama. Portanto, não ocorreu mistura do material, com compostos clorados, em nenhuma etapa da fabricação e reciclagem mecânica.

O teste prévio de amarelamento foi realizado para se ter uma estimativa do comportamento dos materiais (virgem e reciclado) frente às lâmpadas fluorescentes e de LED, com tempo de exposição de até três semanas. Neste ensaio totalizou-se, aproximadamente, $480 \mathrm{~h}$ de exposição, podendo se estimar o uso da luminária em torno de 100 dias, com ela ligada 5h/dia.

Para ter um resultado mais concreto será necessário mais tempo de exposição e medidas num equipamento apropriado, contudo visualmente as amostras não apresentaram nenhuma deformidade ou amarelamento. Levando em consideração o número de corpos de prova utilizados e a massa da luminária foram necessários aproximadamente 72 copos de $200 \mathrm{ml}$ (Figura 7) ou 180 copos termoplásticos de $50 \mathrm{ml}$ (Figura 8). 

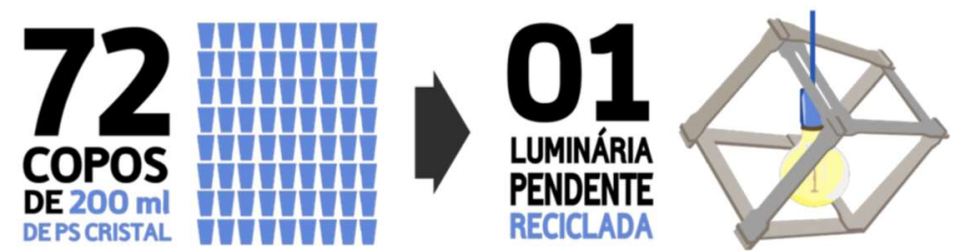

Figura 7: Número de copos de $200 \mathrm{ml}$ para construção da luminária pendente

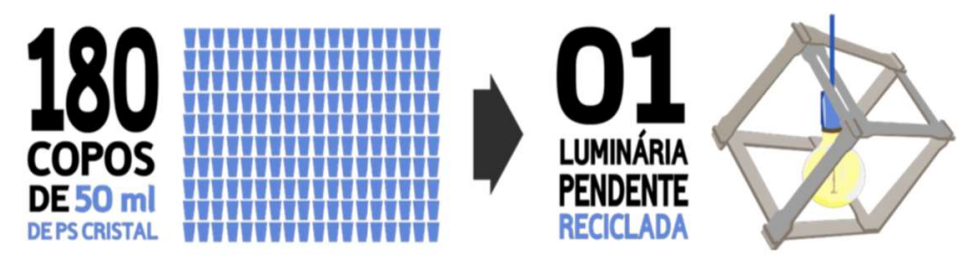

Figura 8: Número de copos de $50 \mathrm{ml}$ para construção da luminária pendente

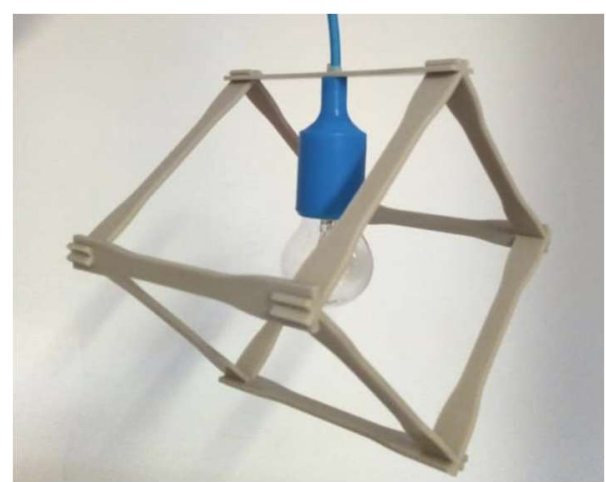

Figura 9: Luminária pendente construída sem adição de pigmento

A luminária foi montada manualmente, encaixando 12 corpos de prova, formando um cubo vazado e foi adicionado cabo, bocal e lâmpada (Figura 9). Com intuito de demonstrar outras formas que podem ser feitas, na Figura 10, utilizou-se pigmentos amarelo e roxo na injeção dos corpos de prova.

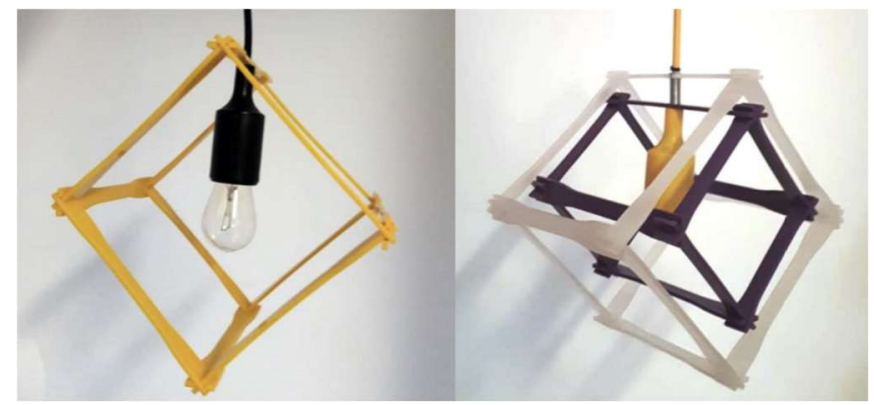

Figura 10: Exemplos possíveis de luminárias pendentes com adição de pigmentos.

\section{CONCLUSÕES}

Os copos descartáveis pós-consumo de uso exclusivo para água facilitaram o desenvolvimento do projeto, tendo apenas uma demora na etapa de cortá-los, por ser executada manualmente, ou seja, caso fosse utilizado um triturador esta seria mais rápido e eficaz. Na parte do processamento do material reciclado foram verificados alguns problemas por causa da leveza e de ser fino, mas esta questão foi ajustada com o aumento da temperatura, tanto na extrusão quanto da injeção, fazendo com que o PS fluísse sem problemas e alterações no resultado. Nas análises de espectroscopia na região do infravermelho e no ensaio mecânico de tração, o PS reciclado se mostrou mais elástico que o PS virgem, 
explica-se tal comportamento possivelmente devido aos aditivos e/ou mistura com PSAI utilizados na fabricação dos copos descartáveis.

O poliestireno, mesmo sendo reciclado, mantém as propriedades próximas ao PS cristal virgem nos testes de chama e no teste de fusão e no teste de ausência de cloro (teste de Beilstein). No teste prévio de amarelamento não foram notadas diferenças visuais na coloração ou alguma deformação devido ao aquecimento pela iluminação direta, porém, para a obtenção de resultados mais precisos seria necessário o teste em equipamento apropriado. Os testes realizados foram satisfatórios e, de maneira geral, condizem com os dados já apresentados na literatura para diferentes composições de poliestireno cristal virgem e/ou reciclado. Além disso, o PS reciclado mostrou-se mais elástico que o PS virgem, propriedade mecânica que tornou a luminária pendente mais resistente e abriu possibilidades de utilizar o PS reciclado para confecção de outros objetos.

Dado o exposto, a reciclagem mecânica secundária de copos descartáveis de pós-consumo para a construção de luminárias pendentes de PS reciclado mostrou ser uma alternativa promissora, embasada no modelo de economia circular, empregando um valor comercial a um produto de origem residual. Além disso, colabora para a diminuição do impacto ambiental que o consumo exorbitante e o descarte indevido dos copos descartáveis causam ao ecossistema. Propostas como essa visam encontrar um caminho mais harmônico e responsável entre sociedade, natureza e economia.

\section{REFERÊNCIAS}

ARAÚJO, E. M.; CARVALHO, L. H.; FOOK, M. V. L.; D'ALMEIDA, J. R. M.. Propriedades mecânicas de blendas de PS/resíduo de borracha: Influência da concentração, granulometria e método de moldagem. Polímeros, v.7, n.3, 1997. DOI: https://doi.org/10.1590/S010414281997000300008

AST. Standard Test Method for Tensile Properties of Plastics. 2003.

AYELERU, O. O.; DLOVA, S.; FREEMAN, N.; KUPOLATI, W. K.; OLUBAMBI, A.. Development and Size Distribution of Polystyrene/ZnO nanofillers. Procedia Manufacturing, v.30, p.194-199, 2019. DOI: https://doi.org/10.1016/i.promfg.2019.02.028

BARBOSA, L. C. A.. Espectroscopia no Infravermelho na caracterização de compostos orgânicos. Viçosa, 2007.

BOTAN, R.; GONÇALVES, N. A.; MORAES, S. B.; LONA, L. M. F.. Preparação e avaliação de nanocompósitos de poliestireno - hidróxido duplo lamellar HDL de ZnAl organofuncionalizado com laurato/palmitato. Polímeros, v.25, n.1, 2015. DOI: https://doi.org/10.1590/0104$\underline{1428.1798}$

CALLISTER JUNIOR, W. D.; RWTHWISCH, D. G.. Materials Science and Engineering: an Introduction. John Wiley \& Sons, 1991.

COLE, M.; LINDEQUE, N. K.; HALSBAND, C.; GALLOWAY, T. S.. Microplastics as contaminants in the marine environment: a review. Marine Pollution Bulletin, v.62, n.12, p.2588-2597, 2011. DOI: https://doi.org/10.1016/j.marpolbul.2011.09.025
FERREIRA, F. M. O.; NETO, A. L.; WEBER, J. K.. Materiais utilizados para proteção de equipamentos sensíveis: a importância da biodegradação em solo simulado. In: CONGRESSO BRASILEIRO DE POLÍMEROS, 13. Anais. Natal, 2015.

FORLIN, F. J.; FARIA, J. A. F.. Considerações Sobre a Reciclagem de Embalagens Plásticas: polímeros. Ciência e Tecnologia, v.12, n.1, p.1-10, 2002. DOI: https://doi.org/10.1590/S0104-14282002000100006

JALAL, N. M.; JABUR, A. R.; HAMZA, M. S.; ALLAM, S.. Preparation, Microstructure and Morphology of Electrospun Sulfonated Polystyrene Films for Proton Exchange Membrane Hydrogen Fuel Cell. Energy Procedia, v.157, p. 1494-1505, 2019.

DOI:https://doi.org/10.1016/i.egyr.2019.11.012

KOONGOLLA, J. B.; ANDRADY, A. L.; KUMARA, P. B. T. P.; GANGABADAGE, C. S.. Evidence of microplastics pollution in coastal beaches and waters in southern Sri Lanka. Marine Pollution Bulletin, v.137, p.277-284, 2018. DOI: https://doi.org/10.1016/i.marpolbul.2018.10.03

KOREZ, S.; GUTOW, L.; SABOROWSKI, R.. Microplastics at the strandlines of Slovenian beaches. Marine Pollution Bulletin, v.145, p.334-342, 2019. DOI: https://doi.org/10.1016/j.marpolbul.2019.05.054

KURNIAWAN, S. B.; IMRON, M. F.. The effect of tidal fluctuation on the accumulation of plastic decris in the Wonorejo River Estuary, Surabaya, Indonesia.

Environmental Technology \& Innovation, v.15, 2019. DOI: 
https://doi.org/10.1016/j.eti.2019.100420

MEHMANDOST, N.; SORIANO, L. S.; LUCENA, R.; GOUDARZI, N.. Recycled polystyrene-cotton composites, giving a second life to plastic residues for environmental remediation. Journal of Environmental Chemical Engineering, v.7, n. 5, 2019. DOI: https://doi.org/10.1016/j.jece.2019.103424

MOTTA, L. A. C.; VIERA, J. G.; OMENA, T. H.; FARIA, F. A. C.; RODRIGUES FILHO, G.; ASSUNÇÃO, R. M. N.. Mortar modified with sulfonated polystyrene produced from waste plastic cups. Revista IBRACON de Estruturas e Materiais, v. 9, n.5, 2016. DOI: https://doi.org/10.1590/S1983$\underline{41952016000500007}$

MROWIEC, B.. Plastics in the circular economy (CE). Environmental Protection and Natural Resources, v. 29 p.16-19, 2018. DOI: https://doi.org/10.1177/0734242X19845041

PALER, M. K. O.; MALENAB, M. C. T.; MARALIT, J. R.; NACORDA, H. M.. Plastic waste occurrence on a beach off southwestern Luzon, Philippines. Marine Pollution Bulletin, v.141, p.416-419, 2019. DOI: https://doi.org/10.1016/i.marpolbul.2019.02.006

PENG, L.; FU, D.; QI, H.; LAN, C. Q.; YU, H.; GE, C.. Micro- and nano-plastics in marine environment: source, distribution and threats: a review. Science of The Total Environment, v. 698, 2020. DOI:

https://doi.org/10.1016/j.scitotenv.2019.134254

PLASTICSEUROPE. The Compelling Facts About Plastics an Analysis of Plastics Production, Demand and Recovery for 2006 in Europe. Plastics Europe, 2008.

PLASTICSEUROPE. Plastics: the facts of 2017: An Analysis of European Plastics Production, Demand and Waste Data. Plastics Europe, 2017.

RANGEL-BUITRAGO, N.; CASTRO-BARROS, J. D.; GRACIA, A. C.; VILLADIEGO, J. D. V.; WILLIAMS, A. T.. Litter impacts on beach/dune systems along the Atlantico Department, the Caribbean Coastline of Colombia. Marine Pollution Bulletin, v.137, p.35-44, 2018. DOI: https://doi.org/10.1016/j.marpolbul.2018.10.009

RIZZI, M.; RODRIGUES, F. L.; MEDEIROS, L.; ORTEGA, I.; RODRIGUES, L.; MONTEIRO, D. S.; KESSLER, F.; PROIETTI, M.
C.. Ingestion of plastic marine litter by sea turtles in southern Brazil: abundance, characteristics and potential selectivity. Marine Pollution Bulletin, v.140, p.536-548, 2019. DOI: https://doi.org/10.1016/j.marpolbul.2019.01.054

SCHNURR, R. E. J.; ALBOIU, V.; CHAUDHARY, M.; CORBETT, R. A.; QUANZ, M. E.; SANKAR, K.; SRAIN, H. S.; THAVARAJAH, V.; XANTHOS, D.; WALKER, T. R.. Reducing marine pollution from single-use plastics (SUPs): A review. Marine Pollution Bulletin, v.137, p.157-171, 2018. DOI: https://doi.org/10.1016/j.marpolbul.2018.10.001

SIMEONOVA, A.; CHUTURKOVA, R.. Marine litter accumulation along the Bulgarian Black Sea coast: categories and predominance. Waste Management, v.84, p.182-193, 2019. DOI: https://doi.org/10.1016/j.wasman.2018.11.001

SPINACÉ, M. A. S.; PAOLI, M. A. A.. Tecnologia da Reciclagem de Polímeros. Química Nova, v.28, n.1, p.65-72, 2005. DOI: https://doi.org/10.1590/S0100-40422005000100014

STRAPASSON, R.. Valorização do polipropileno através de sua mistura e reciclagem. Dissertação (Mestrado em Engenharia Mecânica) - Universidade Federal do Paraná, Curitiba, 2004.

TURKU, I.; KARKI, T.; PUURTINEN, A. Durability of wood plastic composites manufactured from recycled plastic. Heliyon, v.4, n.3, 2018.

DOI:https://doi.org/10.1016/i.heliyon.2018.e00559

VILAPLANA, F.; AMPERO, R. G.; KARLSSON, S.. Degradation of recycled high-impact polystyrene. Simulation by reprocessing and thermos- oxidation. Polymer Degradation and Stability, v.91, n.9, p.2163-2170, 2006. DOI: https://doi.org/10.1016/j.polymdegradstab.2006.01.007

WRIGHT, S. L.; THOMPSON, R. C.; GALLOWAY, T. S.. The physical impacts of microplastics on marine organisms: a review. Environmental Pollution, v.178, p.483-492, 2013. DOI: https://doi.org/10.1016/j.envpol.2013.02.031

ZANIN, M.; MANCINI, S. D.. Resíduos Plásticos e Reciclagem: aspectos gerais e tecnologia. São Carlos: 2004.

A CBPC - Companhia Brasileira de Produção Científica (CNPJ: 11.221.422/0001-03) detém os direitos materiais desta publicação. Os direitos referem-se à publicação do trabalho em qualquer parte do mundo, incluindo os direitos às renovações, expansões e disseminações da contribuição, bem como outros direitos subsidiários. Todos os trabalhos publicados eletronicamente poderão posteriormente ser publicados em coletâneas impressas sob coordenação da Sustenere Publishing, da Companhia Brasileira de Produção Científica e seus parceiros autorizados. Os (as) autores (as) preservam os direitos autorais, mas não têm permissão para a publicação da contribuição em outro meio, impresso ou digital, em português ou em tradução. 